\title{
Effects of dietary supplementation with polyphenols on meat quality in Saanen goat kids
}

\author{
Roberta Cimmino ${ }^{1 *}$ D, Carmela M. A. Barone², Salvatore Claps ${ }^{3}$, Ettore Varricchio ${ }^{4}$, Domenico Rufrano ${ }^{3}$, \\ Mariangela Caroprese ${ }^{5}$, Marzia Albenzio ${ }^{5}$, Pasquale De Palo ${ }^{6}$, Giuseppe Campanile ${ }^{7}$ and Gianluca Neglia ${ }^{7}$
}

\begin{abstract}
Background: Diet supplementation with polyphenols is a novel strategy to improve meat quality in livestock, by preventing oxidative deterioration of lipids and protein. Polyphenols have beneficial effects on both human and animal health and can be obtained from several sources, such as olive mill wastewaters (OMWW). These are severe environmental pollutants and therefore may be recycled and utilized in other sectors. The aim of this study was to evaluate growth performance, meat characteristics, fatty acid composition, antioxidant status, different forms of myoglobin and malondialdehyde formation in kids who received a diet supplemented with polyphenols obtained from OMWW. Weaned goat kids $(n=18)$ were divided into two homogenous groups: control (C) group $(n=9)$ received a fattening standard diet while the other group $(n=9)$ received the same diet, supplemented with $3.2 \mathrm{mg} /$ day of polyphenols powder extract (PE group). Average daily gain (ADG) was calculated 10 days apart throughout the study. After 78 days, the kids were slaughtered and $\mathrm{pH}$ and carcass yield were evaluated. Longissimus thoracis et lumborum muscle was collected and utilized for chemical analysis, meat quality evaluation and oxidative stability.
\end{abstract}

Results: No differences were recorded in ADG, carcass weight, pH and dressing between the two groups. Furthermore a similar meat proximate composition, texture and color was observed. Dietary polyphenols supplementation significantly $(P<0.01)$ decreased short chains $(<C 12: 0)(2.93+0.50$ and $0.35+0.40 \mathrm{~g} / 100 \mathrm{~g}$ of fatty acids, for $\mathrm{C}$ and PE Group, respectively), and saturated (49.22 \pm 2.39 and $39.51 \pm 1.95 \mathrm{~g} / 100 \mathrm{~g}$, in C and PE Group, respectively) fatty acids. Furthermore, a higher $(P<0.05)$ proportion of monounsaturated $(34.35 \pm 2.84$ and $42.22 \pm 2.32 \mathrm{~g} / 100 \mathrm{~g}$, in $C$ and PE Group, respectively) fatty acids was recorded. Malondialdehyde formation was significantly $(P<0.05)$ lower in PE compared to C Group $(0.25 \pm 0.005$ and $0.15 \pm 0.005$, in C and PE Group, respectively).

Conclusions: Polyphenols dietary supplementation has positive effects on kid meat, improving fatty acid profile and reducing malondialdehyde contents. Furthermore the utilization of OMWW as the source of polyphenols may represent an innovative strategy to re-utilize agri-food industry wastes.

Keywords: Polyphenols, Kids, Fatty acids, Sensory evaluation, Malondialdehyde

\section{Background}

An increased awareness of the consumers was recently observed regarding red meat's production and consumption. A typical example was the latest report of the World Health Organization (WHO), which classified the consumption of red meat as "probably carcinogenic for man" [1], although, as outlined by other authors [2], there are still a number of

\footnotetext{
* Correspondence: r.cimmino@anasb.it

${ }^{1}$ Italian Buffalo Breeders Association, V. Petrarca 42/44, 81100 Caserta, Italy Full list of author information is available at the end of the article
}

gaps in the current knowledge about this topic. Furthermore, eating red meat has been correlated with higher incidence of chronic diseases [3]. For this reason there has been an increased interest for new breeding techniques which confer potential health benefits to the consumers [4].

The supplementation of ruminants diet with antioxidants is considered an effective strategy for changing and ameliorating the fatty acid composition of meat in response to consumer demands [4]. In fact, it has been observed that

(c) The Author(s). 2018 Open Access This article is distributed under the terms of the Creative Commons Attribution 4.0 International License (http://creativecommons.org/licenses/by/4.0/), which permits unrestricted use, distribution, and 
the inclusion of linseed and fish oil on the lamb diet may have a negative impact on the oxidative stability and on physicochemical properties of the meat [5]. In addition, the changes that occur in the muscle during the post-mortem period may create an unbalanced proportion between the antioxidant and pro-oxidant capability, increasing the risks of oxidative damage [6]. The antioxidant status of the muscle is the main factor affecting oxidative deterioration in meat [7]. Oxidative deterioration of lipids and proteins in meat could adversely affect its nutritional quality and shelf life, reducing flavor, color and quality of meat, with a negative impact on meat consumption.

Thus, it is essential to preserve the quality and the safety of the meat by attenuating oxidative deterioration. Recently, the interest of food processing industries in the use of natural antioxidants rather than synthetic counterparts was increased, for either low environmental impact and economical reasons [8]. Furthermore natural antioxidants are well accepted by the consumers, because they are considered safe and healthy [9]. For these reasons, many studies have been carried out to develop new natural antioxidants, especially from plants [8], among which polyphenols. Polyphenols are a large family of more than 8000 natural compounds derived from plants and characterized by the presence of a phenol ring in their structure [10, 11]. Epidemiological, clinical and nutritional studies strongly support the evidence that dietary phenolic compounds are effective in the prevention of common diseases, including cancer, neurodegenerative diseases and gastrointestinal disorders [12]. Furthermore, a large number of studies suggest several immunomodulatory and anti-inflammatory properties of these compounds in humans $[13,14]$. Some studies, performed in livestock, reported the positive effects of diet supplementation with polyphenols on pigs and chicken health. $[11,15,16]$. In addition, it has been hypothesized that dietary supplementation with polyphenols would increase beneficial lipids and oxidative stability of myoglobin and reduce the content of malondialdehyde (MDA) [see 11 for review].

Polyphenols can be obtained from several sources. One of these is the olive oil sector, particularly important in Mediterranean countries, such as Spain (the leading producer), Italy, Greece, Turkey, Syria and Tunisia. Olive mill wastewaters (OMWW) are the main pollutant by-phase and traditional suction systems Mills. The management of OMWW is a serious environmental issue for the presence of organic compounds that turn OMWW into phytotoxic materials [17]. Nevertheless, OMWW contains valuable resources, such as polyphenols, which can represent about $10 \%$ of OMWW dry weight [18]. Some olive oil derived-compounds, such as hydroxytyrosol, have an important role in preventing cardiovascular diseases [19]. Thus OMWW could be recycled and utilized in other sectors, such as animal feeding, to reduce its environmental impact.

Therefore, the objective of this study was to investigate the effects of the supplementation with polyphenols obtained from OMWW in the diet of Saanen goat kids on growth performance and meat quality. In particular, meat proximate composition, texture and colorimetric properties, fatty acid composition, lipid oxidation and the level of the different forms of myoglobin of Longissimus thoracis et lumborum (LTL) muscle were evaluated.

\section{Methods}

Animals, experimental design and diet composition

All experimental procedures were approved by the Ethical Committee on Animal Research of the University of Naples (Protocol number: 2014/0105988 of 1st December 2014), and the study was carried out in accordance with EU Directive 2010/63/EU for animal experiments.

The trial was performed on 18 Saanen female kids maintained in the experimental farm of CREA (Research Centre for Animal Production and Aquaculture) located in Bella (PZ), in the South of Italy, at $40^{\circ} 75^{\prime}$ latitude and $15^{\circ} 67^{\prime} \mathrm{W}$ longitude, and $802 \mathrm{~m}$ above sea level. The kids were allowed natural suckling until weaning, that occurred at 69 days of age. After weaning the animals were divided into 2 homogeneous groups, according to age and live body weight (LW), recorded at both birth and weaning: Control $(C)$ group $(n=9)$ : received a fattening standard diet (Table 1); Polyphenols extract (PE) group $(n=9)$ :

Table 1 Ingredients (\%) and proximate composition (\% of dry matter) of the basal diet administered to the kids throughout the experimental period

\begin{tabular}{lll}
\hline Ingredients (\%) of concentrate administered & \\
\hline Maize meal & 60 & \\
Faba bean (Viccia faba minor) & 15 & \\
Alfalfa pellets & 5 & \\
Soybean meal & 5 & \\
Wheat bran & 10 & Dehydrated alfalfa \\
Oat & 5 & 85.6 \\
& Concentrate & 8.3 \\
Dry Matter (g/100 g weight) & 87.5 & 19.5 \\
Ash & 2.7 & 25.6 \\
Crude protein & 11.8 & 37.5 \\
Crude fiber & 6.19 & 34.3 \\
Neutral detergent fiber & 18.2 & 9.8 \\
Acid detergent fiber & 8.9 & 1.9 \\
Lignin & 2.1 & 25.6 \\
Ether extract & 3.8 & - \\
Non structural carbohydrates & 63.5 & 56.8 \\
Starch & & \\
\hline
\end{tabular}


received the same diet of control group, supplemented with a powder of polyphenols extract from OMWW (3.2 $\mathrm{mg} /$ day, see below). The amount of polyphenols powder was defined according to antioxidant activity (see below) and some studies performed in growing lambs [5].

The kids of each group were individually penned in boxes $\left(1 \mathrm{~m}^{2}\right)$ throughout the study that lasted 78 days. All kids had free access to water and received the same ration, consisting of alfalfa hay ad libitum and a starter concentrate administered in increasing amount according to the growth following the recommendation of National Research Council [20]. Feed was administered twice a day, at 8.00 and 16.00 and polyphenols powder was mixed on daily bases with the concentrate in the PE Group. The inclusion level of polyphenols extract was variable throughout the study according the amount of administered concentrate from $1.70 \%$ at the start of the trial to $0.83 \%$ in the last week (1.16\% on average). Feed intake was determined from orts (refusals) collected daily in the morning (when present) before the next feed administration. The amount and the composition of orts were utilized to calculate the dry matter (DM) intake and the composition of the ingested diet. Individual feedstuff and orts were sampled every 15 days and the analyses were carried out as per AOAC (Association of Official Analytical Chemists) procedures [21] after drying at $65{ }^{\circ} \mathrm{C}$ and mechanical reduction of the samples (granulometry $1 \mathrm{~mm}$ for all analyses). The chemical composition of individual feedstuff is reported in Table 1.

Each animal was individually weighed 10 days apart and average daily gain (ADG) was calculated by dividing the difference between two consecutive LW measurements (LW1 and LW2) with the number of days elapsed (LW2 - LW1/days).

\section{Polyphenols determination}

Polyphenols extract from OMWW was obtained and characterized as reported by Parrillo et al. [22]. Briefly, the polyphenolic extract was obtained by membrane separation of OMWW according to previous studies [23] and the main phenolic compounds were identified by HPLC (LC-4000 Series Integrated HPLC Systems, JASCO, Japan) according to Azaizeh et al. [18] (Table 2). Total phenols content in OMWW extract was determined by the Folin-Ciocalteu method [24]. The antioxidant activity of the OMWW extract was evaluated by using the free radical ABTS (2,2-Azino-bis-3-ethylbenzothiazoline-6-sulfonic acid), according to the procedures described by Re et al. [25].

\section{Slaughtering procedure and muscle sampling}

At the end of the experimental period (147 days of age), all the kids were left overnight with ad libitum access to
Table 2 Main phenolic compounds of olive mill wastewaters (OMWW) extracts

\begin{tabular}{|c|c|c|}
\hline Main compounds & $\mathrm{mg} / \mathrm{kg}$ & Percent \\
\hline Hydroxytyrosol & 20,829 & 21.27 \\
\hline Flavonoid & 3278 & 3.35 \\
\hline Tyrosol & 3947 & 4.03 \\
\hline Caffeic acid & 9991 & 10.20 \\
\hline Verbascoside & 17,449 & 17.82 \\
\hline $\begin{array}{l}\text { Hydroxytyrosol derivatives (OHTY-glycol, } \\
\text { OHTY-glucoside, 3,4-diidrossifenilethanol - } \\
\text { 3,4-DHPEA Elenolic acid mono-Aldehyde, } \\
\text { 3,4-DHPEA- AC hydroxytyrosol acetate) }\end{array}$ & 26,826 & 27.40 \\
\hline $\begin{array}{l}\text { Verbascoside derivatives (isoverbascoside, } \\
\beta \text {-hydroxyverbascoside, } \beta \text {-hydroxyisoverbascoside) }\end{array}$ & 6498 & 6.64 \\
\hline $\begin{array}{l}\text { Other derivatives of cinnamic acid (cinnamic acid, } \\
o-, p \text { - coumaric acid, ferulic acid) }\end{array}$ & 3372 & 3.44 \\
\hline $\begin{array}{l}\text { Caffeic acid derivatives (chlorogenic acid, } \\
\text { neochlorogenic acid, 1-O-caffeoylquinic acid, } \\
\text { 3,5-O-dicaffeoylquinic acid) }\end{array}$ & 4681 & 4.78 \\
\hline Other polyphenols & 1055 & 1.08 \\
\hline Total polyphenols (TPC) (mg/kg) & 97,926 & \\
\hline Antioxidant activity (mmolitrolox/kg sample) & 8521 & \\
\hline
\end{tabular}

water and slaughtering procedures were carried out in accordance to the EU Regulation 2009/1099/EC on the protection of animals at the time of killing. The animals were stunned by captive bolt and the exsanguination from the jugular vein was carried out. After slaughtering, evisceration and dressing, each carcass was weighed and the $\mathrm{pH}$ was measured $45 \mathrm{~min}$ post-mortem in the LTL muscle (between 11th and 13th thoracic vertebra), using an automatic digital pH-metertest-205 (TestoInc, Sparta, NJ, USA), equipped with a penetrating electrode. The probe was calibrated with $\mathrm{pH} 4$ and 7 standard buffer solutions. The dressed carcass comprises the body after removing skin, head, fore feet (at the carpal-metacarpal joint), hind feet (at the tarsal-metatarsal joint), lung, heart, liver, spleen, kidneys, kidney fat, and gastrointestinal tract fat. Furthermore, the stomachs (rumen, reticulum, omasum, and abomasum) and the postruminal tract (intestine and caecum) were removed. Dressing percentage (DP) was calculated according to the following formula:

$$
\mathrm{DP}=(\text { hot carcass weight/live weight }) \times 100
$$

All carcasses were stored at $2{ }^{\circ} \mathrm{C}$ for $24 \mathrm{~h}$. Ultimate $\mathrm{pH}$ was assessed $24 \mathrm{~h}$ post-mortem on LTL muscle and the carcasses were weighed again. After that, a professional butcher removed the LTL muscle, between the sixth thoracic and 5th lumbar vertebra, from the right side of each carcass. $L T L$ samples were stored at $4{ }^{\circ} \mathrm{C}$ and used 
for chemical analysis, meat quality evaluation and oxidative stability. Furthermore, $\mathrm{pH}$ was also assessed $48 \mathrm{~h}$ postmortem on LTL muscle as described above.

\section{Chemical analyses}

All analyses were carried out in the Laboratories of the Department of Veterinary Medicine and Animal Production (DMVPA), and Department of Agriculture Sciences (DIA) of University of Naples Federico II (Italy). The chemical composition of LTL muscle was determined on refrigerated $\left(4{ }^{\circ} \mathrm{C}\right)$ samples according to the AOAC procedures [26] by using a Foodscan equipment (Food Scan ${ }^{\mathrm{Tm}} \mathrm{Lab} 78,810$ ). Each sample was analyzed in duplicate.

\section{Texture measurements}

Tenderness was evaluated on meat cooked in a thermostatically controlled water bath at $90{ }^{\circ} \mathrm{C}$ on day 1 after slaughtering. To monitor temperature achieved in the middle of the sample $\left(70{ }^{\circ} \mathrm{C}\right)$, a portable digital thermometer (TEMP7 thermometer digital microprocessor for Pt100 probes, TECNAFOOD MO, IT) was used. After cooking the samples were dried with paper, in order to eliminate the moisture on the surface, and held in a cooler at $4{ }^{\circ} \mathrm{C}$ before coring. A minimum of four cores of $1.27 \mathrm{~cm}^{2}$ from each LTL muscle were obtained parallel to the longitudinal orientation of the muscle fibers. The Instron 5565 with a Warner-Bratzler shear (WBS) device and crosshead speed set at $100 \mathrm{~mm} / \mathrm{min}$ and a load cell of $500 \mathrm{~kg}$ [27] was used. According to Girard et al. [28], the measured parameters were Shear myofibrillar force (SMF) and Warner-Bratzler Shear Force (WBSF) both expressed in $\mathrm{kg}$. Indeed in a shear force curve some peaks of less importance may be observed, before and after maximum positive peak shear force (WBSF). Bouton \& Harris [29] related these first small peaks to the myofibrillar component of shear force coinciding with initial yield (SMF). WBSF minus SMF estimates the connective tissue contribution.

\section{Instrumental color}

The color of the meat was determined on the surface of samples using a U3000 spectrophotometer, equipped with integrating sphere (Hitachi, Tokyo, Japan). Although illuminant $\mathrm{D}_{65}$ is largely utilized, the use of Illuminant $\mathrm{A}$ is recommended by AMSA [30]. For this reason color coordinates, employing the CIEL*a*b* system with two illuminants, $\mathrm{D}_{65}(6500 \mathrm{~K})$ and $\mathrm{A}(2856 \mathrm{~K})$ and $10^{\circ}$ standard observer, were Lightness $\left(\mathrm{L}^{*}\right)$; redness $\left(\mathrm{a}^{*}\right)$, and yellowness $\left(b^{*}\right)$ were also calculated, according to AMSA [30]. The color analyses were carried out in duplicate every day, from $24 \mathrm{~h}$ post-mortem until day 7 , on samples (diameter $2.54 \mathrm{~cm}$, thick $2 \mathrm{~cm}$ ) stored at $4{ }^{\circ} \mathrm{C}$. The samples were placed on white trays and wrapped with oxygen-permeable film.
Color difference $\left(\Delta E^{* *}\right)$ between each day of storage and the day 0 was calculated as follows:

$$
\Delta \mathrm{E}^{*}=\left(\Delta \mathrm{L}^{* 2}+\Delta \mathrm{a}^{* 2}+\Delta \mathrm{b}^{* 2}\right)^{1 / 2}
$$

Where $A L^{*}, \Delta a^{*}$ and $\Delta b^{*}$ are the differences between $L^{*}$, $a^{*}$ and $b^{*}$ values at time 0 and the individual readings each day.

Metmyoglobin (MMb), deoxymyoglobin (DMb) and oxymyoglobin (OMb) percentages were estimated according to [30] on the basis of the Reflex Attenuance (A) at the isobestic points 572, 525, 473 and $730 \mathrm{~nm}(\mathrm{~nm})$. The Reflex Attenuance (A) was identified as:

$$
A=\log (1 / R)
$$

where $\mathrm{R}$ expresses the reflectance at a specific wavelength in decimal (0.30 rather than $30 \%)$.

Therefore from the Reflex Attenuance (A), it was possible to estimate the three forms of myoglobin:

$$
\begin{aligned}
& \% \mathrm{MMb}=[1.395-(\mathrm{A} 572-\mathrm{A} 730 / \mathrm{A} 525-\mathrm{A} 730)] \times 100 \\
& \% \mathrm{DMb}=\left[2.375^{*}(1-((\mathrm{A} 473-\mathrm{A} 730) \cdot /(\mathrm{A} 525-\mathrm{A} 730)] \times 100\right. \\
& \% \mathrm{OMb}=[(100-(\% \mathrm{MMb}+\% \mathrm{DMb})]
\end{aligned}
$$

\section{Fatty acid analysis}

Fatty acid composition of the meat was assessed on fresh samples on day 1 post-slaughtering. The muscle was blended in a food processor and the lipids were extracted from $5 \mathrm{~g}$ samples in duplicate, using chloroform:methanol $(2: 1, v / v)[31]$. The extracted lipids were transmethylated to their fatty acid methyl esters (FAME) according to Christie [32]. The amount of fatty acid (g/100 g of FAME) was determined by gas chromatography using a chromatograph (DANI fast GC, Italy), with a flame ionization detector and equipped with a capillary column (TR-CN 100) $(60 \mathrm{~m} \times 0.25 \mathrm{~mm}$ diameter $\times 20 \mu \mathrm{m})$. Helium was used as carrier gas at a flow rate of $1.2 \mathrm{~mL} / \mathrm{min}$. The split ratio was 50:1, the injector was set at $280{ }^{\circ} \mathrm{C}$ and the detector at $240{ }^{\circ} \mathrm{C}$. The oven temperature was programmed and held at $80{ }^{\circ} \mathrm{C}$ for $5 \mathrm{~min}$, then increased to $165{ }^{\circ} \mathrm{C}$ at $5{ }^{\circ} \mathrm{C} / \mathrm{min}$, held at $165{ }^{\circ} \mathrm{C}$ for $1 \mathrm{~min}$, and then increased to $260{ }^{\circ} \mathrm{C}$ at $3{ }^{\circ} \mathrm{C} / \mathrm{min}$, and then held at $260{ }^{\circ} \mathrm{C}$ for $1 \mathrm{~min}$.

Identification of each fatty acid was obtained by comparing the chromatogram with the reference standard mixture of Supelco 37 component series FAME MIX (Supelco Bellefonte, PA, USA) and a mixture of CLA isomers (Nu-Chek-Prep, Inc., Elysian, MN, USA). Retention time and area of each peak were calculated using the Clarity software (Clarity v.2.4.1.77, Data Apex Ltd., 2005). The atherogenic index $(\mathrm{AI})$ and the thrombogenic index (TI) were obtained by using the following equations [33]. 


$$
\begin{aligned}
\mathrm{AI}: & {[(4 \times \mathrm{C} 14: 0)+\mathrm{C} 16: 0+\mathrm{C} 18: 0] } \\
& /[\Sigma \text { } \mathrm{MUFA}+\Sigma \text { PUFA-n6 }+\Sigma \text { PUFA-n3 }] \\
\mathrm{TI}: & {[(\mathrm{C} 14: 0+\mathrm{C} 16: 0+\mathrm{C} 18: 0)} \\
& /(0.5 \mathrm{xMUFA})+(0.5 \times \text { PUFA-n6 }) \\
& +(3 \times \text { PUFA-n3 })+(\text { PUFA-n3/PUFA-n6 })]
\end{aligned}
$$

\section{Evaluation of lipid oxidation}

The evaluation of lipid oxidation in meat was based on the determination of malondialdehyde (MDA), a secondary lipid oxidation product ( $\mathrm{nmol} / \mu \mathrm{g}$ of meat). MDA was determined by a specific kit (Lipid Peroxidation (MDA) Assay Kit, Sigma-Aldrich, USA) according to the manual instructions. MDA was quantified by spectrophotometric analysis (Model 680 Microplate Reader, Biorad, Italy), at a wave length of $532 \mathrm{~nm}$. MDA content was evaluated at 1 , 3 and 7 days post-slaughtering.

\section{Statistical analysis}

The experimental data were subjected to one way analysis of variance (ANOVA) using the linear model of the SAS software [34], following confirmation of normality and homogeneity of variance. The influence of dietary treatment (polyphenols supplemented diet or control diet),storage (day 1, 3 and 7) and their interaction (dietary treatment $\mathrm{x}$ storage) were used as main factors to analyze color parameters, MDA levels and the different forms of myoglobin. Results are presented as mean values with standard error of mean (SEM). The mean were compared using the Student's $t$-test. The differences were considered significant when $P$ values were lower than 0.05 , whereas a tendency was considered for $P<0.10$.

\section{Results}

\section{Animal performance and carcass characteristics}

The effects of polyphenols supplementation on growth performance and carcass properties are shown in Table 3. A similar ADG from weaning to slaughter and a similar weight at slaughter were observed in the two Groups. Furthermore, carcass weights and yields were similar between groups at 0 and $24 \mathrm{~h}$ post mortem (Table 3). No significant differences were observed in the $\mathrm{pH}$ decline values between the groups both at $45^{\prime}$ minutes and $24 \mathrm{~h}$ post-mortem (Table 3 ).

\section{Meat quality}

A similar meat chemical composition was recorded in $\mathrm{C}$ and PE group (Table 4).

The texture assay highlights a double peak $(\mathrm{SMF}=1 \mathrm{st}$ peak and $\mathrm{WBSF}=2$ nd peak)in 9/9 animals of $\mathrm{C}$ samples
Table 3 Age and weight at weaning and at slaughter, average daily gain (ADG), feed consumption, carcass characteristics and dressing percentage in Control (C) and polyphenols extract (PE) group (mean values \pm SEM)

\begin{tabular}{llll}
\hline & \multicolumn{2}{l}{ Groups } & \multicolumn{2}{l}{ Significance } \\
\cline { 2 - 3 } & $\mathrm{C}$ & $\mathrm{PE}$ & $\mathrm{P}$ \\
\hline Age at weaning (days) & $69.8 \pm 1.30$ & $68.9 \pm 1.50$ & 0.65 \\
Age at slaughtering (days) & $146.8 \pm 1.30$ & $145.9 \pm 1.50$ & 0.65 \\
Weaning body weight (kg) & $11.0 \pm 0.75$ & $10.7 \pm 0.86$ & 0.78 \\
Final body weight (kg) & $17.9 \pm 0.99$ & $18.6 \pm 1.28$ & 0.69 \\
Weight gain (kg) & $6.94 \pm 0.60$ & $7.93 \pm 0.61$ & 0.26 \\
ADG (kg/g) & $0.09 \pm 0.01$ & $0.10 \pm 0.01$ & 0.26 \\
Concentrate intake (kg/day) & $0.30 \pm 0.00$ & $0.29 \pm 0.00$ & 0.33 \\
Hay intake (kg/day) & $0.68 \pm 0.01$ & $0.67 \pm 0.01$ & 0.39 \\
DM intake (kg/day) & $0.84 \pm 0.02$ & $0.85 \pm 0.03$ & 0.57 \\
Carcass weight at & $10.0 \pm 0.51$ & $10.0 \pm 0.77$ & 0.98 \\
slaughtering (kg) & & & \\
Carcass weight at 24 h (kg) & $9.7 \pm 0.50$ & $9.7 \pm 0.74$ & 0.99 \\
pH at slaughtering & $6.8 \pm 0.11$ & $6.8 \pm 0.12$ & 0.90 \\
pH at 24 h & $5.8 \pm 0.03$ & $5.8 \pm 0.03$ & 0.64 \\
Dressing at slaughtering (\%) & $55.8 \pm 1.41$ & $54.0 \pm 0.48$ & 0.15 \\
Dressing at 24 h (\%) & $54.6 \pm 1.39$ & $52.3 \pm 0.45$ & 0.14 \\
\hline
\end{tabular}

compared to 3/9 animals of PE counterparts. SMF values obtained by deformation curves where a double peak was evident, tended to be higher $(P=0.06)$ in $\mathrm{PE}$ compared to $C$ group, whereas similar WBSF values were recorded (Table 5).

The color coordinates detected by using the two illuminants (A and D65) were similar between the two groups. In fact, although the illuminant A would give more emphasis on the proportion of red wave lengths, no significant differences were recorded in lightness $\left(\mathrm{L}^{*}\right)$; redness $\left(\mathrm{a}^{*}\right)$, yellowness $\left(\mathrm{b}^{*}\right)$ between the two groups and throughout the storage. Furthermore, no significant interaction storage $\mathrm{x}$ treatment was assessed. Slight differences were observed in color differences $\left(\Delta \mathrm{E}^{*}\right)$ during the

Table 4 Proximate meat composition of LTL muscle in control (C) and polyphenols extract (PE) group (mean values \pm SEM)

\begin{tabular}{llll}
\hline & \multicolumn{2}{l}{ Groups } & \multicolumn{2}{l}{\begin{tabular}{l} 
Significance \\
\cline { 2 - 3 }
\end{tabular}} & $\mathrm{C}$ & $\mathrm{PE}$ & $\mathrm{P}$ \\
\hline Moisture (\%) & $66.6 \pm 0.46$ & $64.1 \pm 0.35$ & 0.11 \\
Fat (\%) & $13.7 \pm 0.46$ & $16.5 \pm 0.31$ & 0.09 \\
Protein (\%) & $18.3 \pm 0.30$ & $18.7 \pm 0.40$ & 0.43 \\
Collagen (\%) & $2.3 \pm 0.28$ & $3.0 \pm 0.16$ & 0.14 \\
Ash (\%) & $0.91 \pm 0.12$ & $0.84 \pm 0.05$ & 0.58 \\
$\mathrm{pH}^{*}$ & $6.1 \pm 0.01$ & $6.2 \pm 0.01$ & 0.51 \\
\hline
\end{tabular}

${ }^{*} \mathrm{pH}$ was assessed on LTL sample $48 \mathrm{~h}$ after slaughtering 
Table 5 Shear myofibrillar force (SMF) and Warner-Bratzler Shear Force (WBSF) recorded in the LTL muscle of control (C) and polyphenols extract (PE) group (mean values \pm SEM)

\begin{tabular}{llll}
\hline & Groups & & Significance \\
\hline & $\mathrm{C}$ & $\mathrm{PE}$ & $\mathrm{P}$ \\
WBSF, kg & $4.5 \pm 0.10$ & $4.6 \pm 0.10$ & 0.86 \\
SMF, kg & $0.53 \pm 0.07$ & $1.14 \pm 0.33$ & 0.06 \\
\hline
\end{tabular}

first three days of storage in the meat of PE Group compared to the control when analyzed by illuminant A, while an opposite trend was recorded with the illuminant D65. In any case, no statistical differences were recorded (Fig. 1) and subsequently the changes showed the same trend with both illuminants.

Neither dietary treatment $(P=0.77$ and $P=0.99$, for $\mathrm{OMb}$ and $\mathrm{MMb}$, respectively) nor storage period $(P=0.33$ and $P=0.10$, for $\mathrm{OMb}$ and $\mathrm{MMb}$, respectively) and their interaction $(P=0.98$ and $P=0.95$, for $\mathrm{OMb}$ and $\mathrm{MMb}$, respectively) influenced the estimated levels of myoglobin forms. As expected, during the storage period, the estimated level of $\mathrm{MMb}$ tended to increase in both groups, while the levels of $\mathrm{OMb}$ decreased until 3 days and increased after 7 days of storage (Table 6).

\section{Fatty acid composition and oxidative stability}

The fatty acids composition of LTL intramuscular lipids in the two groups is shown in Table 7. Dietary polyphenols supplementation determined a decrease of short chain fatty acids $(<\mathrm{C} 12: 0)$ as well as of Myristic (C14:0) Myristoleic (C14:1), Pentadecanoic (C15:0), Palmitic (C16:0) and Palmitoleic (C16:1) acids.

A significant lower $(P<0.01)$ percentage of saturated (SFA) and higher $(P<0.05)$ proportion of monounsaturated (MUFA) fatty acids were recorded in PE group compared to $\mathrm{C}$ group. However, no differences were recorded in the total amount of polyunsaturated fatty acids (PUFA), while the unsaturated fatty acids (UFA):SFA ratio was influenced by the treatment $(P<0.01)$. Furthermore, the PUFA:SFA $(\mathrm{P}: \mathrm{S})$ ratio tended to be higher $(P=0.09)$ in $\mathrm{PE}$ group, compared to $C$ group. Therefore, the meat of $\mathrm{PE}$ group was also characterized by a significant lower AI index $(P<0.05)$ and TI index $(P<0.01)$, compared to the control counterparts.

In relation to lipid oxidation, a significant effect of dietary treatment was observed. In particular, lower $(P<0.05)$ MDA values were recorded in PE group, compared to $C$ group $(0.25 \pm 0.005$ and $0.15 \pm 0.005$ in Group $C$ and $P E$, respectively), as showed in Fig. 2, whereas neither the storage $(P=0.96)$ nor the interaction storage $\mathrm{x}$ dietary treatment $(P=0.97)$ influence the results.

\section{Discussion}

This study aimed to ascertain the influence of dietary polyphenols administration on growth performance and meat quality in kids. Contrasting results have been reported on the effects of plant extracts administration on live weight gain, carcass weight and dressing percentage either in ruminants [35, 36], and not ruminants [11,37]. According to some authors [37] no adverse effect on growth performance or protein and aminoacids digestibility were recorded in broilers after $2.5 \mathrm{~g} / \mathrm{kg}$ of grape seed extracts administration, while a delayed growth rate was observed after $5 \mathrm{~g} / \mathrm{kg}$ of supplementation. On the contrary, other authors [38] report an increase of final body weight and DWG in broilers fed dietary polyphenol-rich grape seed. Few studies have been performed in ruminants till now. Similar growth performance were observed in growing lambs fed a diet supplemented with grape pomace, vitamin E or grape seeds extract [39]. Similarly, the supplementation of the diet with pomegranate seed pulp [40] or with vitamin E, Turmeric powder or Andrographis paniculata powder [35] did not affect the growth of kids.

Also in our study, growth performance was not influenced by dietary polyphenols supplementation, but some
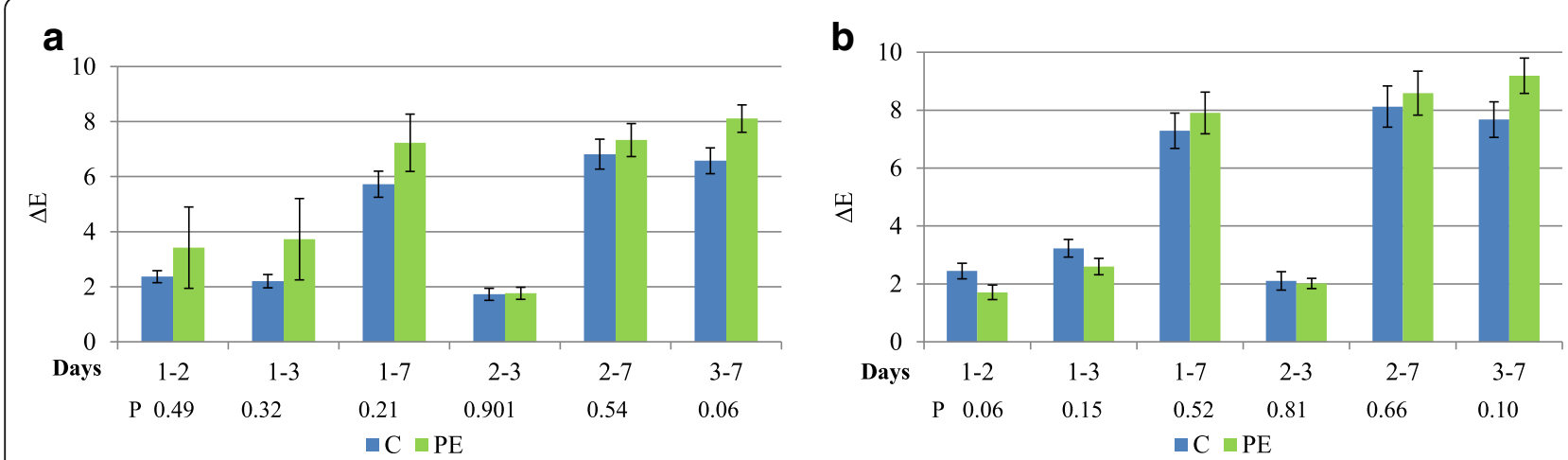

Fig. 1 Difference of color $(\triangle E)$ by 1 to 7 days of storage with illuminant D65 (a) and illuminant $A(\mathbf{b})$, in control (c) and polyphenols extract (PE) group (blue) and treated (green) group. The error bars represent standard error 
Table 6 Estimated levels (mean percentage \pm SEM) of metmyoglobin (MMb) and oxymyoglobin (OMb), in the LTL muscle of control (C) and treated (PE) group, throughout the storage at $4{ }^{\circ} \mathrm{C}$

\begin{tabular}{|c|c|c|c|c|c|}
\hline & Groups & 1 & 2 & 3 & 7 \\
\hline \multirow[t]{2}{*}{$\mathrm{MMb}$} & C & $40.73 \pm 1.88$ & $45.28 \pm 1.18$ & $53.57 \pm 1.67$ & $61.78 \pm 3.60$ \\
\hline & PE & $40.99 \pm 1.94$ & $47.67 \pm 1.52$ & $54.41 \pm 1.88$ & $63.37 \pm 3.94$ \\
\hline \multirow[t]{2}{*}{$\mathrm{OMb}$} & C & $68.93 \pm 2.70$ & $34.04 \pm 3.04$ & $15.07 \pm 3.24$ & $43.87 \pm 9.42$ \\
\hline & PE & $62.66 \pm 7.02$ & $38.13 \pm 4.83$ & $21.42 \pm 5.69$ & $51.48 \pm 10.28$ \\
\hline
\end{tabular}

aspects need to be considered. First of all about 8000 phenolic compounds have been identified in different plant species [11] and in different amounts, creating serious difficulties in making a comparison among the studies. Furthermore, fewer information is present on bioavailability of phenolic compounds in ruminants and their effects on bacterial rumen population, fermentation and absorption [10] compared to non-ruminants [11]. It can not be ruled out that different compounds and/or different amounts of polyphenols may lead to different results.

Also the proximate composition of the meat in our trial was not influenced by dietary polyphenols supplementation. This result is in agreement with previous studies carried out in goat, in which dietary herbal antioxidants [35] or vitamin E [36] were administered. Similarly, vitamin $\mathrm{E}$ supplementation did not affect carcass traits and dressing percentage in lambs [41]. Regarding the texture, the meat of control kids showed the occurrence in all samples of an initial yield putatively related to the myofibrillar component of shear force and classified as shear myofibrillar force [29]. On the contrary, a single peak was recorded in 6/9 animals of the PE group. For this reason, SMF values tended to be higher in PE group compared to $\mathrm{C}$ group. However, no differences were recorded for WBSF. This last result may indicate a similar collagen content of the meat recorded in the two groups. The evaluation of the contribution of either myofibrillar and connective tissue to meat texture after the cooking process can not be obtained without performing additional measurements [28]. Some authors [42, 43] suggested that the connective tissue contribution may be recorded by subtracting the initial yield from the shear force peak: although the shear force does not accurately represent the contribution of connective tissue to muscle tenderness [27, 44, 45], it may be hypothesized a larger contribution of the connective component to the final hardness in the control group, compared to the PE counterparts. To our knowledge, few studies have been performed to evaluate texture parameters in small ruminants after polyphenols diet supplementation. Carnosic acid supplementation seems to be an useful tool to improve meat sensory characteristics in fattening lambs,
Table 7 Mean fatty acid composition (g/100 g of FAME) of LTL muscle in control (C) and polyphenols extract (PE) group (mean values \pm SEM)

\begin{tabular}{|c|c|c|c|}
\hline \multirow[b]{2}{*}{ Fatty Acids } & \multicolumn{2}{|l|}{ Groups } & \multirow{2}{*}{$\begin{array}{l}\text { Significance } \\
\mathrm{P}\end{array}$} \\
\hline & $\bar{C}$ & $P E$ & \\
\hline$<\mathrm{C} 12: 0$ & $2.93 \pm 0.50^{B}$ & $0.35 \pm 0.40^{\mathrm{A}}$ & 0.001 \\
\hline C12:0 & $0.45 \pm 0.36$ & $0.20 \pm 0.07$ & 0.06 \\
\hline C14:0 & $4.00 \pm 0.58^{b}$ & $2.28 \pm 0.47^{\mathrm{a}}$ & 0.04 \\
\hline C14:1 & $0.46 \pm 0.06^{B}$ & $0.23 \pm 0.05^{\mathrm{A}}$ & 0.01 \\
\hline C15:0 & $0.58 \pm 0.06^{b}$ & $0.41 \pm 0.05^{\mathrm{a}}$ & 0.04 \\
\hline C16:0 & $23.81 \pm 0.85^{\mathrm{B}}$ & $20.22 \pm 0.70^{\mathrm{A}}$ & 0.01 \\
\hline C16:1 & $3.05 \pm 0.41^{b}$ & $1.63 \pm 0.33^{a}$ & 0.02 \\
\hline C17:0 & $1.12 \pm 0.17$ & $1.17 \pm 0.14$ & 0.79 \\
\hline C17:1 & $1.33 \pm 0.17$ & $0.91 \pm 0.14$ & 0.08 \\
\hline C18:0 & $15.60 \pm 1.25$ & $14.31 \pm 1.02$ & 0.43 \\
\hline C18:1 cis & $27.16 \pm 3.15^{a}$ & $36.01 \pm 2.57^{b}$ & 0.05 \\
\hline C18:1 trans & $0.08 \pm 0.73$ & $1.64 \pm 0.60$ & 0.12 \\
\hline $\mathrm{C} 18: 2 \mathrm{cis}$ & $12.22 \pm 1.07$ & $13.64 \pm 0.88$ & 0.32 \\
\hline C18:2 trans n6 & $0.48 \pm 0.05$ & $0.37 \pm 0.04$ & 0.09 \\
\hline C18:3 n6 y-linolenic & $0.10 \pm 0.03$ & $0.07 \pm 0.02$ & 0.43 \\
\hline C20:0 & $0.05 \pm 0.04$ & $0.03 \pm 0.03$ & 0.74 \\
\hline C20:1 & $1.62 \pm 0.15$ & $1.59 \pm 0.12$ & 0.89 \\
\hline C20:2 n6 & $0.10 \pm 0.03$ & $0.05 \pm 0.02$ & 0.31 \\
\hline CLA cis 9-trans 11 & $1.22 \pm 0.12$ & $1.02 \pm 0.10$ & 0.24 \\
\hline $\mathrm{C} 20: 3 \mathrm{n} 3$ & $1.00 \pm 0.40$ & $1.22 \pm 0.33$ & 0.67 \\
\hline C20:4 n6 & $0.72 \pm 0.75$ & $1.63 \pm 0.61$ & 0.36 \\
\hline C22:0 & $0.32 \pm 0.12$ & $0.27 \pm 0.10$ & 0.76 \\
\hline $\mathrm{C} 22: 6 \mathrm{n} 3$ & $0.63 \pm 0.40$ & $0.24 \pm 0.33$ & 0.47 \\
\hline$C 24: 0$ & $0.33 \pm 0.20$ & $0.26 \pm 0.16$ & 0.77 \\
\hline C24:1 & $0.63 \pm 0.38$ & $0.20 \pm 0.31$ & 0.39 \\
\hline PUFA n6 & $13.62 \pm 0.96$ & $15.77 \pm 1.30$ & 0.31 \\
\hline PUFA n3 & $1.63 \pm 0.75$ & $1.47 \pm 0.61$ & 0.86 \\
\hline n6/n3 & $8.36 \pm 0.86$ & $10.73 \pm 0.91$ & 0.41 \\
\hline$\Sigma$ SFA & $49.22 \pm 2.39^{B}$ & $39.51 \pm 1.95^{\mathrm{A}}$ & 0.01 \\
\hline ¿MUFA & $34.35 \pm 2.84^{\mathrm{a}}$ & $42.22 \pm 2.32^{b}$ & 0.05 \\
\hline$\Sigma$ PUFA & $16.47 \pm 2.02$ & $18.26 \pm 1.65$ & 0.51 \\
\hline UFA:SFA & $1.08 \pm 0.13^{A}$ & $1.55 \pm 0.07^{B}$ & 0.01 \\
\hline PUFA:SFA & $0.34 \pm 0.04$ & $0.47 \pm 0.05$ & 0.09 \\
\hline $\mathrm{Al}$ & $1.28 \pm 0.19^{b}$ & $0.69 \pm 0.16^{a}$ & 0.03 \\
\hline $\mathrm{Tl}$ & $2.13 \pm 0.32^{\mathrm{B}}$ & $1.38 \pm 0.26^{\mathrm{A}}$ & 0.01 \\
\hline
\end{tabular}

Different superscript letters within the same row indicate significant differences ( ${ }^{\text {a., b. }}: P<0.05 ;{ }^{\text {A.B. }}: P<0.01$ )

Note: $\Sigma$ SFA $=(<C 12: 0+C 12: 0+C 14: 0+C 15: 0+C 16: 0+C 17: 0+C 18: 0+C 20: 0+$ $\mathrm{C} 22: 0+\mathrm{C} 24: 0), \Sigma$ MUFA $=(\mathrm{C} 14: 1+\mathrm{C} 16: 1+\mathrm{C} 17: 1+\mathrm{C} 18: 1 \mathrm{cis}+\mathrm{C} 18: 1$ trans $+\mathrm{C} 20: 1+$ C24:1), $\Sigma$ PUFA $=(\Sigma C L A+\Sigma n 3+\Sigma n 6)$, UFA:SFA $=[(\Sigma M U F A+\Sigma P U F A) / \Sigma S F A]$,

PUFA:SFA $=(\Sigma P U F A / \Sigma S F A)$,

Al: [(4 x C14:0)+C16:0+C18:0] / [LMUFA + EPUFA-n6 + EPUFA-n3], TI: $[((\mathrm{C} 14: 0+\mathrm{C} 16: 0+\mathrm{C} 18: 0) /(0.5 \times M U F A)+(0.5 \times$ PUFA-n6) + (3xPUFA-n3) + (PUFA-n3 / PUFA-n6)] 


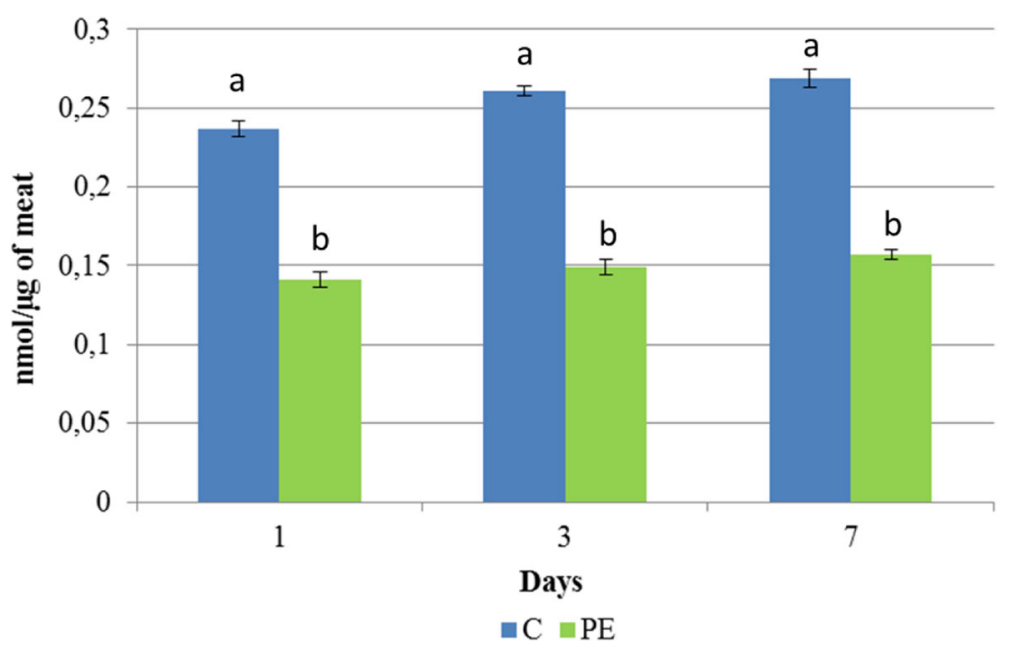

Fig. 2 Lipid peroxidation in meat during the days of storage (expressed in MDA nmol/ $\mu \mathrm{g}$ of meat), the error bars represent standard error

similarly to Vitamin E [46]. On the contrary, quercetin dietary supplementation seemed to worsen texture in fattening lambs [47].

No differences were observed in our study on color stability between the two groups, in accordance with previous reports carried out in lambs fed naringin supplementation [48]. The color is an important meat quality attribute because it is the first aspect which attracts consumers when choosing fresh meat. Color stability is mainly due to the increase in myoglobin oxidation and consequent metmyoglobin formation and accumulation. Kid's meat is generally characterized by lower $a^{*}$ values compared to beef and lamb meat, outlining the difference in myoglobin concentration that reduces the discoloration. The effects of antioxidants on color stability in small ruminants have been analyzed in several studies in both kids [36, 40, 49] and lambs [39, 50] with contrasting results. According to some authors [40] no differences were recorded in kids fed pomegranate seed pulp on $\mathrm{L}^{*}$, while an increase of $a^{*}$ together with a decrease of $b^{*}$ was assessed. Similarly, no influence of vitamin E supplementation on color parameters was recorded in kids reared both in pen groups or maintained on pastures, although the rearing system significantly influenced meat color [36]. Dietary supplementation with antioxidants (vitamin $\mathrm{E}$ and flavonoids in particular) influences color parameters in some [39, 51], but not all [50] studies performed in growing lambs. Other authors reported a significantly lighter meat after polyphenols administration in lambs, probably because of their action in chelating iron and consequent low haemoglobin concentration [52]. Definitely, the results obtained in this study suggest that the concentration of $\mathrm{MMb}$ and $\mathrm{OMb}$ in meat, and consequently meat color, was not affected by dietary polyphenols supplementation. Only a slight lower, although not significant, $\Delta \mathrm{E}^{*}$ was observed in $\mathrm{PE}$ group, when detected by illuminant $\mathrm{A}$. The latter determined higher value placing more emphasis on the proportion of red wave lengths. This aspect is important when the differences between treatments have to be highlighted, as outlined by AMSA [30]. Similar results were obtained by other authors [7] by using a dietary supplementation with a blend of $80 \%$ canola oil and $20 \%$ palm oil, and were justified by physical changes that occur during the storage, and not directly related to the oxidative process [49], since no significant effects on color and oxidative stability of myoglobin was recorded. However, it can not be ruled out that the amount of dietary polyphenols was not able to highlight significant effects, thus further studies are needed to evaluate different dosages.

In our study polyphenols extract supplementation affected the fatty acid profile of the meat. In particular, a significantly higher concentration of MUFA, together with a reduction of SFA was observed in PE Group compared to control, but no effects were recorded on PUFA. The acidic composition of meat in ruminants is generally different from that of non-ruminants. The PUFA/SFA ratio is lower because of the hydrogenation of UFA in the rumen, while this process does not occur in monogastrics that absorb UFA without any transformation in the gastrointestinal tract. Therefore, several UFA that are normally present in the diet of ruminants, are saturated and can not be present in derived food [53]. Thus, the diet plays the main role in the modification of fatty acid composition and rumen microbial population, as demonstrated by the evidence that rumen population activity on dietary UFA hydrogenation depends by the administered diet [54]. Several studies carried out in vitro [55-57] demonstrated that some phenolic compounds can modulate rumen fermentation, reducing the rate of 
biohydrogenation of fatty acids. In particular, some plants with high polyphenols content would be able to lower the biohydrogenation of PUFA in the rumen, increasing their by-pass and, consequently, the formation of CLA [56]. Similarly, an increase of C18 PUFA was recorded after $24 \mathrm{~h}$ in vitro incubation of an experimental diet with leaf fractions of papaya, extracted with hexane or chloroform [57]. However, only an increase of C18:1 (oleic acid) was recorded in our study, together with a similar n6 and n3 PUFA and a similar concentration of CLA, although a slight increase of C18:1 trans was observed. It is known that the presence of CLA in the tissues depends from the desaturation of C18:1 trans-11, catalyzed through $\Delta 9$ desaturase [58]. However, the amount of C18:1 trans-11 in ruminant meat and milk is influenced by its hydrogenation to stearic acid (C18:0) or other C18:1 isomers at the rumen level by the microbial population [59]. It can not be ruled out that the amount of polyphenols extract utilized in our study might need to be increased to further improve the fatty acid profile of the meat. In a recent study [36], a lower amount of SFA, together with an increase of MUFA and lower AI and TI indexes were observed in kids after $450 \mathrm{mg} / \mathrm{kg}$ of vitamin $\mathrm{E}$ diet supplementation compared to control counterparts. Adeyemi et al. [4], reported a lower concentration of C16:0 and C16:1 n7 in goats fed 4 and $8 \%$ oil blend compared with control, justified by displacement or dilution effects of other fatty acids and by the decrease in the activity of lipogenic enzymes responsible for the synthesis of medium chain FA or the preferential incorporation of long chain FA from diet and/or adipose tissues. In a recent trial [5] dietary supplementation with red wine extract significantly increased the levels of C20:5 n3 in lambs, but no influence on oxidative stability was recorded. In any case, the P:S ratio, recognized as a healthy index, tended to be higher in PE group compared to control. Because of the hydrogenation of PUFA by the microbial population, the meat of ruminants is usually characterized by a low P:S ratio [60], leading to an increased risk of cardiovascular diseases. Therefore, the modification of fatty acid profile obtained in the present study suggests that dietary polyphenols administration may result in kid meat with beneficial effects on human health.

A further positive effect of polyphenols administration was recorded on oxidative stability of the meat, as demonstrated by the reduction of MDA, an aldehyde commonly utilized as marker of secondary lipid oxidation in meat and characterized by mutagenic and carcinogenic properties. In fact, MDA changes the link between lipoproteins and scavenger receptors on the surface of macrophages causing cholesterol ester buildup and foam cell formation and may also react with deoxyadenosine and deoxyguanosine, nitrogenous DNA bases, potentially causing mutations [61].
Although the values recorded in our study may be considered a limiting point from where rancid flavor overpowers flavor in beef [62] and MDA concentration is probably overestimated by spectrophotometric method [63], a significant decrease was observed in PE group compared to $\mathrm{C}$ group.

The use of antioxidant substances, such as high polyphenols content in the diet, reduces lipid peroxidation and the formation of DNA additives, by inhibiting the formation of MDA. A possible explanation of the antioxidant activity of polyphenols can be sought in the potential of chelating metal ions [64]: they are able to bind iron, forming insoluble compounds at the gastrointestinal lumen level and making it unavailable for absorption. Iron has been recognized as the most likely catalyst to promote lipid peroxidation by the formation of free radicals formed following the Fenton reaction [65]. This is supported by several studies carried out in chicken poultry [37], rats [66] and pigs [67], in which the inclusion in the diet of polyphenols obtained by different sources significantly reduces plasma iron concentration. Therefore, the reduction of iron absorption may explain the lower MDA content recorded in $\mathrm{PE}$ group compared to $\mathrm{C}$ group. However, it can not be ruled out that this phenomenon may be due to an enhancement of muscle oxidative stability, via an increased expression of $\Delta 9$ desaturase enzyme, as demonstrated in lambs fed tannins supplementation [68], or to the increase of endogenous antioxidant defense [69]. In any case, our results are in agreement with other studies in which a significant reduction in MDA formation following polyphenols administration was recorded in goat [40], chicken [70] and turkey meat [71].

\section{Conclusions}

In conclusion, although no effects were observed on meat proximate composition, texture and colorimetric properties, the results of this study demonstrated that the supplementation of the diet with polyphenols extracts by OMWW is able to improve the fatty acid profile of kid meat, together with a reduction of MDA content. The utilization of this source of polyphenols may represent a novel strategy to re-utilize agri-food industry wastes as additives for livestock, meeting either meat industry and consumers requests of natural additives in animal farming. In any case, further studies are needed to test different doses of polyphenols and to better understand the role that the different categories of these compounds may have on meat quality.

\footnotetext{
Abbreviations

$\triangle E^{*}$ : Color difference; A: Reflex attenuance; a*: Redness; ADG: Average daily gain; Al: Atherogenic index; ANOVA: analysis of variance; AOAC: Association of official analytical chemists; b*: Yellowness; C group: Control group;

CREA: Research centre for animal production and aquaculture;

DIA: Department of agriculture sciences; DM: Dry matter;

DMb: Deoxymyoglobin; DMVPA: Department of veterinary medicine and
} 
animal production; DP: Dressing percentage; FAME: Fatty acid methyl esters; L*: Lightness; LTL: Longissimus thoracis et lumborum; LW: Live body weight; MDA: Malondialdehyde; MMb: Metmyoglobin; MUFA: Monounsaturated fatty acid; OMb: Oxymyoglobin; OMWW: Olive mill wastewaters; PE group: Polyphenols extract group; PUFA: Polyunsaturated fatty acid; SEM: Standard error of mean; SFA: Saturated fatty acid; SMF: Shear myofibrillar force; TI: Thrombogenic index; TPC: Total polyphenols; UFA: unsaturated fatty acid; WBS: Warner-bratzler shear; WBSF: Warner-bratzle Shear Force

\section{Acknowledgements}

The authors gratefully acknowledge Mr. Roberto Di Matteo for his technical support during meat quality analyses.

The authors gratefully acknowledge Dr. Emiliana Capurro, PhD, Dr. Trevor

Cullen (Dublin, Ireland) and Dr. Claire Teter for language editing.

\section{Funding}

This research did not receive any specific grant from funding agencies in the public, commercial, or not-for-profit sectors.

\section{Availability of data and materials}

The datasets during the current study are available from the corresponding author on reasonable request.

\section{Authors' contributions}

RC, GC and GN designed the experiment. EV, SC and MC prepared the polyphenols and determined their antioxidant activity. DR, SC, CMAB, MA and RC carried out the experiments. CMAB, RC and PDP performed the statistical analysis of the results. RC, GN, PDP and MC prepared the draft of the manuscript. All authors contributed to the analysis of the data, discussion of results and implications and commented on the manuscript at all stages. All authors read and approved the final manuscript.

\section{Ethics approval and consent to participate}

All experimental procedures were approved by the Ethical Committee on Animal Research of the University of Naples (Protocol number: 2014/0105988 of 1st December 2014), and the study was carried out in accordance with EU Directive 2010/63/EU for animal experiments.

\section{Competing interests}

The authors declare that they have no competing interests.

\section{Publisher's Note}

Springer Nature remains neutral with regard to jurisdictional claims in published maps and institutional affiliations.

\section{Author details}

${ }^{1}$ Italian Buffalo Breeders Association, V. Petrarca 42/44, 81100 Caserta, Italy. ${ }^{2}$ Department of AgriculturalSciences, Federico II University, Via Università 133, 80055 Portici, Naples, Italy. ${ }^{3}$ Research Centre for Animal Production and Aquaculture (CREA, S.S. 7 Appia, 85051, Bella Muro, PZ, Italy. ${ }^{4}$ Department of Sciences and Technologies, University of Sannio, V. Port'Arsa 11, 82100 Benevento, Italy. ${ }^{5}$ Department of Agricultural Food and Environmental Sciences, University of Foggia, Via Napoli 25, 71122 Foggia, Italy. "Department of Veterinary Medicine, University "Aldo Moro" of Bari, S.P. per Casamassima, km 3, Valenzano, 70010 Bari, Italy. ${ }^{7}$ Department of Veterinary Medicine and Animal Production, Federico II University, V. F. Delpino 1 , 80137 Naples, Italy.

Received: 29 September 2017 Accepted: 1 June 2018 Published online: 11 June 2018

\section{References}

1. International Agency for Research on Cancer. Carcinogenicity of consumption of red and processed meat. Lyon France: Report of the International Agency for Research on cancer. Press release no 240; 2015.

2. Domingo JL, Nadal M. Carcinogenicity of consumption of red meat and processed meat: a review of scientific news since the IARC decision. Food Chem Toxicol. 2017;105:256-61

3. Wolk A. Potential health hazards of eating red meat. J Intern Med. 2017 281:106-22
4. Adeyemi KD, Shittu RM, Sabow AB, Ebrahimi M, Sazili AQ. Influence of die and postmortem ageing on oxidative stability of lipids, myoglobin and myofibrillar proteins and quality attributes of gluteus medius muscle in goats. PLoS One. 2016:11:e0154603.

5. Muíño I, Apeleo E, de la Fuente J, Pérez-Santaescolástica C, Rivas-Cañedo A, Pérez $C$, et al. Effect of dietary supplementation with red wine extract or

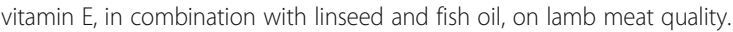
Meat Sci. 2014;98:116-23.

6. Sabow AB, Sazili AQ, Aghwan AA, Zulkifli I, Goh YM, Ab-Kadir MZA, et al. Changes of microbial spoilage lipid-protein oxidation and physicochemical properties during postmortem refrigerated storage of goat meat. Anim Sci J. 2016;87:816-26

7. Adeyemi KD, Sabow AB, Shittu RM, Karim R, Karsani SA, Sazili AQ. Impact of chill storage on antioxidant status, lipid and protein oxidation, color, drip loss and fatty acids of semimembranosus muscle in goats. CyTA-J Food. 2015; https://doi.org/10.1080/19476337.2015.1114974.

8. Jiang J, Xiong Y. Natural antioxidants as food and feed additives to promote health benefits and quality of meat products: a review. Meat Sci. 2016;120:107-17.

9. Naveena BM, Sen AR, Vaithiyanathan S, Babji Y, Kondaiah N. Comparative efficacy of pomegranate juice, pomegranate rind powder extract and BHT as antioxidants in cooked chicken patties. Meat Sci. 2008;80:1304-8.

10. Gessner DK, Ringseis R, Eder K. Potential of plant polyphenols to combat oxidative stress and inflammatory processes in farm animals. J Anim Physio An Nutr (Berl). 2017;101:605-28.

11. Lipiński K, Mazur M, Antoszkiewicz Z, Purwin C. Polyphenols in monogastric nutrition: a review. Ann Anim Sci. 2017:17:41-58.

12. Zhang PY. Polyphenols in health and disease. Cell Biochem Biophys. 2016; 73:649-64.

13. Pandey KB, Rizvi SI. Plant polyphenols as dietary antioxidants in human health and disease. Oxidative Med Cell Longev. 2009;2:270-8.

14. Zhang H, Tsao R. Dietary polyphenols, oxidative stress and antioxidant and anti-inflammatory effects. Curr Opin Food Sci. 2016:8:33-42.

15. Brenes A, Viveros A, Chamorro S, Arija I. Use of polyphenol-rich grape by-products in monogastric nutrition. A review Anim Feed Sci Tech. 2016;211:1-17.

16. Laudadio V, Ceci E, Lastella NM, Tufarelli V. Dietary high-polyphenols extra-virgin olive oil is effective in reducing cholesterol content in eggs. Lipids Health Dis. 2015:14:5.

17. Federici F, Fava F, Kalogerakis N, Mantzavinos C. Valorisation of agro-industrial by-products effluents and waste: concept opportunities and the case of olive mill wastewaters. J Chem Technol Biot. 2009:84: 895-900.

18. Azaizeh $H$, Halahlih F, Najami N, Brunner D, Faulstich M, Tafesh A. Antioxidant activity of phenolic fractions in olive mill wastewater. Food Chem. 2012:134:2226-34

19. Fernández-Bolaños JG, López O, López-García MA, Marset A. Biological properties of hydroxytyrosol and its derivatives. In: Boskou D, editor. Olive oil - constituents. Quality. Health properties and bioconversions. Croatia: InTech open; 2012. p. 375-96.

20. NRC (National Research Council). Nutrient requirements of small ruminants: sheep, goats, cervids and new world camelids. Washington, DC: The National Academies Press; 2007. https://doi.org/10.17226/11654

21. AOAC. Association of official analytical chemists: official methods of analysis. $18^{\text {th }}$ ed. 2004, Arlington, VA, USA: Association of Official Analytical Chemists.

22. Parrillo L, Coccia E, Volpe MG, Siano F, Pagliarulo C, Scioscia E, Varricchio E, Safari O, Eroldogan T, Paolucci M. Olive mill wastewater-enriched diet positively affects growth, oxidative and immune status and intestinal microbiota in the crayfish. Astacusleptodactylus Aquaculture. 2017;473:161-8.

23. Cassano A, Conidi C, Giorno L, Drioli E. Fractionation of olive mill wastewaters by membrane separation techniques. J Hazard Mat. 2013;248249:185-93.

24. Singleton $V L$, Orthofer R, Lamuela-Raventos RM. Analysis of total phenols and other oxidation substrates and antioxidants by means of FolinCiocalteu reagent. Methods Enzymol. 1999:299:152-78.

25. Re R, Pellegrini N, Proteggente A, Pannala A, Yang M, Rice-Evans C. Antioxidant activity applying and improved ABTS radical action decolorization assay. Free Radical Bio Med. 1999;26:1231-7.

26. AOAC. Determination of Fat, Moisture, and Protein in Meat and Meat Products: official Methods of Analysis. 18th ed. Gaithersburg: Method; 2007.

27. American Meat Science Association (AMSA). Research guidelines for cookery, sensory evaluation and instrumental tenderness measurements of 
meat. 2nd Edition Version 1.02. Chicago: Illinois: American Meat Science Association; 2016.

28. Girard I, Bruce HL, Basarab JA, Larsen IL, Aalhus JL. Contribution of myofibrillar and connective tissue components to the Warner-Bratzler shear force of cooked beef. I Meat Sci. 2012;92:775-82.

29. Bouton PE, Harris PV. Factors affecting tensile and Warner-Bratzler shear values of raw and cooked meat. J Texture Stud. 1978;9:395-413.

30. AMSA. Meat color measurements guidelines. Chicago: IL, USA: American Meat Science Association; 2012

31. Folch J, Lees M. Sloane Stanley GH. A simple method for the isolation and purification of total lipides from animal tissues. J Biol Chem. 1957;226:497-509.

32. Christie WW. Preparation of methyl esters-part 2. Lipid Technol. 1990;2:79-80.

33. Ulbricht TLV, Southgate DAT. Coronary hearth disease: seven dietary factors. Lancet. 1991;338:985-92.

34. SAS Institute. SAS procedures guide version 6. 3rd ed. SAS Institute Inc: Cary, NC; 1990.

35. Karami M, Alimon AR, Goh YM, Sazili AQ, Ivan M. Effects of dietary herbal antioxidants supplemented on feedlot growth performance and carcass composition of male goats. Am J Anim Vet Sci. 2010;5:33-9.

36. Yakan A, Ates $C T$, Alasahana S, Odabasioglua F, Unal N, Ozturkc OH, Gungor OF, Ozbeyaz C. Damascus kids' slaughter, carcass and meat quality traits in different production systems using antioxidant supplementation. Small Ruminant Res. 2016;136:43-53.

37. Chamorro S, Viveros A, Centeno C, Romero C, Arija I, Brenes A. Effects of dietary grape seed extract on growth performance, amino acid digestibility and plasma lipids and mineral content in broiler chicks. Animal. 2013;7:555-61.

38. Abu Hafsa SH, Ibrahim SA. Effect of dietary polyphenol-rich grape seed on growth performance, antioxidant capacity and ileal microflora in broiler chicks. J Anim Physiol An Nutr (Berl). 2017; https://doi.org/10.1111/jpn.12688.

39. Guerra-Rivas C, Vieira C, Rubio B, Martínez B, Gallardo B, Mantecón AR, Lavín P, Manso T. Effects of grape pomace in growing lamb diets compared with vitamin E and grape seed extract on meat shelf life. Meat Sci. 2016;116:221-9.

40. Emami A, FathiNasri MH, Ganjkhanlou M, Zali A, Rashidi L. Effects of dietary pomegranate seed pulp on oxidative stability of kid meat. Meat Sci. 2015; 104:14-9.

41. Macit M, Aksakal V, Emsen E, Esenbu ga N, Aksu Ml. Effect of vitamin E supplementation on fattening performance: non carcass components and retail cut percentages and meat quality traits of Awassi lambs. Meat Sci. 2003;64:1-6.

42. Bouton PE, Harris PV, Shorthose WR. Changes in shear parameters of meat associated with structural changes produced by aging, cooking and myofibrillar contraction. J Food Sci. 1975;40:1122-6.

43. Lawrie RA, Ledward DA. Lawrie's meat science. $7^{\text {th }}$ edition. Cambridge England: Woodhead Publishing limited p. 2006;442

44. Bouton PE, Ford AL, Harris PV, Shorthose WR, Ratcliff D, Morgan JHL. Influence of animal age on the tenderness of beef: muscle differences. Meat Sci. 1978;2:301-11.

45. Harris PV, Shorthose WR. Meat texture. In: Lawrie RA, editor. Developments in meat science-4. London, England: Elsevier Applied Science Publishers; 1988. p. 245-86.

46. Morán L, Andrés S, Bodas R, Prieto N, Giráldez FJ. Meat texture and antioxidant status are improved when carnosic acid is included in the diet of fattening lambs. Meat Sci. 2012;91:430-4.

47. Andrés S, Huerga L, Mateo J, Tejido ML, Bodas R, Morán L, Prieto N, Rotolo L, Giráldez FJ. The effect of quercetin dietary supplementation on meat oxidation processes and texture of fattening lambs. Meat Sci. 2014;96:806-11.

48. Bodas R, Prieto N, Jordán MJ, López-Campos O, Giráldez FJ, Morán L, et al. The liver antioxidant status of fattening lambs is improved by naringin dietary supplementation at $0.15 \%$ rates but not meat quality. Animal. 2012; 6:863-70.

49. Morales-delaNuez A, Moreno-Indias I, Falcón A, Argüello A, Sánchez-Macias D, Capote J, Castro N. Effects of various packaging systems on the quality characteristic of goat meat. Asian-Austral J Anim. 2009;22:428-32.

50. Muela E, Alonso V, Campo MM, Sañudo C, Beltrán JA. Antioxidant diet supplementation and lamb quality throughout preservation time. Meat Sci. 2014;98:289-95.

51. Inserra L, Priolo A, Lanza M, Bognanno M, Gravador R, Luciano G. Dietary citrus pulp reduces lipid oxidation in lamb meat. Meat Sci. 2014;96:1489-93.

52. Samman S, Sandström B, Toft MB, Bukhave K, Jensen M, Sørensen SS, Hansen M. Green tea or rosemary extract added to foods reduces non heme-iron absorption. Am J Clin Nutr. 2001;73:607-12.
53. Chilliard Y, Glasser F, Ferlay A, Bernard L, Rouel J, Doreau M. Diet, rumen biohydrogenation and nutritional quality of cow and goat milk fat. Eur J Lipid Sci Technol. 2007;109:828-55.

54. Bessa RJ, Alves SP, Jeronimo E, Alfaia CM, Prates JA, Santos-Silva J. Effect of lipid supplements on ruminal biohydrogenation intermediates and muscle fatty acids in lambs. Eur J Lipid Sci Technol. 2007;109:868-78.

55. Cabiddu A, Salis L, Tweed JK, Molle G, Decandiaa M, Lee M. The influence of plant polyphenols on lipolysis and biohydrogenation in dried forages at different phenological stages: in vitro study. J Sci Food Agric. 2010;90:829-35.

56. Jayanegara A, Kreuzer M, Wina E, Leiber E. Significance of phenolic compounds in tropical forages for the ruminal bypass of polyunsaturated fatty acids and the appearance of biohydrogenation intermediates as examined in vitro. Anim Prod Sci. 2011;51:1127-36.

57. Jafari S, Meng GY, Rajion MA, Jahromi MF, Ebrahimi M. Manipulation of rumen microbial fermentation by polyphenol rich solvent fractions from papaya leaf to reduce green-house gas methane and biohydrogenation of C18 PUFA. J Agric Food Chem. 2016;64:4522-30.

58. Palmquist DL, St-Pierre N, McClure KE. Tissue fatty acid profiles can be used to quantify endogenous rumenic acid synthesis in lambs. J Nutr. 2004;134: 2407-14.

59. Griinari JM, Bauman DE. Biosynthesis of conjugated linoleic acid and its incorporation into meat and milk in ruminants. In: Yurawecz MP, Mossoba MM, JKG K, Pariza MW, Nelson GJ, editors. Advances in conjugated linoleic acid research. Champaign: AOCS press; 1999. p. 180-200.

60. Nieto G, Ros G. Modification of fatty acid composition in meat through diet: effect on lipid peroxidation and relationship to nutritional quality - a review. Lipid peroxidation, Dr. angel Catala: In Tech; 2012. https://doi.org/10. 5772/51114. Available from: https://www.intechopen.com/books/lipidperoxidation/modification-of-fatty-acid-composition-in-meat-through-dieteffect-on-lipid-peroxidation-and-relatio

61. Del Rio D, Stewart AJ, Pellegrini N. A review of recent studies on malondialdehyde as toxic molecule and biological marker of oxidative stress. Nutr Metab Cardiovasc Dis. 2005;15:316-28.

62. Campo MM, Nute GR, Hughes SI, Enser M, Wood JD, Richardson RI. Flavour perception of oxidation in beef. Meat Sci. 2006;72:303-11.

63. Reitznerová A, Šuleková M, Nagy J, Marcincák S, Semjon B, C'ertík M, Klempová T. Lipid peroxidation process in meat and meat products: a comparison study of malondialdehyde determination between modified 2-Thiobarbituric acid spectrophotometric method and reverse-phase high-performance liquid chromatography. Molecules. 2017;22

64. Shahidi F, Janitha PK, Wanasundara PD. Phenolic antioxidants. Critical Reviews in Food Sci Nutr. 1992;32:67-103.

65. Liochev SI, Hausladen A, Beyer WF Jr, Fridovich I. NADPH: ferredoxin oxidoreductase acts as a paraquatdiaphorase and is a member of the soxrs regulon. P Natl AcadSci USA. 1994;91:1328-31.

66. Marouani N, Chahed A, Hedhili A, Hamdaoui MH. Both aluminium and polyphenols in green tea decoction (Camelia sinensis) affect iron status and haematological parameters in rats. Eur J Nutr. 2007:46:453-9.

67. Lee SH, Shinde PL, Choi JY, Kwon IK, Lee JK, Pak SI, Cho WT, Chae BJ. Effects of tannic acid supplementation on growth performance, blood haematology, iron status and faecal microflora in weanling pigs. Livestock Sci. 2010;131:281-6.

68. Vasta V, Priolo A, Scerra M, Hallet KG, Wood JD, Doran O. $\Delta(9)$ desaturase protein expression and fatty acid composition of longissimus dorsi muscle in lambs fed green herbage or concentrate with or without added tannins. Meat Sci. 2009:82:357-64.

69. López-Andrés P, Luciano G, Vasta V, Gibson TM, Biondi L, Priolo A, MuellerHarvey I. Dietary quebracho tannins are not absorbed, but increase the antioxidant capacity of liver and plasma in sheep. Br J Nutr. 2013;110:1-8.

70. Goňi I, Brenes A, Centeno C, Viveros A, Saura-Calixto F, Rebole' A, Arija I, Esteve R. Effect of dietary grape pomace and vitamin $E$ on growth performance, nutrient digestibility and susceptibility to meat lipid oxidation in chickens. Poultry Sci. 2007;86:508-16.

71. Juskiewicz J, Jankowski J, Zielinski H, Zdunczyk Z, Mikulski D, Antoszkiewicz $Z$, Kosmala M, Zdunczyk P. The fatty acid profile and oxidative stability of meat from turkeys fed diets enriched with n-3 polyunsaturated fatty acids and dried fruit pomaces as a source of polyphenols. PLoS One. 2017;12: e0170074. https://doi.org/10.1371/journal.pone.0170074. 